\title{
ANALISIS PENGARUH HEDONISME, RELIGIUSITAS, MOTIVASI, DAN PROMOSI TERHADAP KEPUTUSAN MENABUNG PADA BANK SYARIAH (STUDI KASUS PADA PT BANK BRI SYARIAH, TBK KANTOR CABANG PEMBANTU MAJAPAHIT SEMARANG)
}

\author{
Rokhmania Nurmaeni $^{1}$, Siti Hasanah ${ }^{2}$ \& Mustika Widowati $^{3}$ \\ ${ }_{1,2 \& 3}$ Politeknik Negeri Semarang \\ Email: rnurmaeni@gmail.com, hsnpoetry@gmail.com,mustika2_66@yahoo.com
}

\begin{abstract}
ABSTRAK
Penelitian ini bertujuan untuk menganalisis dan mendapatkan bukti empiris mengenai pengaruh hedonisme, religiusitas, motivasi, dan promosi terhadap keputusan menabung pada bank syariah (studi kasus pada PT Bank BRI Syariah, Tbk Kantor Cabang Pembantu Majapahit Semarang) baik secara simultan maupun parsial. Data yang digunakan dalam penelitian ini adalah data primer yang dikumpulkan menggunakan kuesioner. Populasi dalam penelitian ini adalah seluruh nasabah tabungan pada PT Bank BRI Syariah, Tbk KCP Majapahit Semarang. Sampel dalam penelitian ini berjumlah 110 nasabah tabungan PT Bank BRI Syariah, Tbk KCP Majapahit Semarang. Teknik pengambilan sampel yang digunakan adalah accidental sampling. Model analisis data menggunakan model analisis regresi linier berganda. Sedangkan teknik analisis data menggunakan menggunakan uji statistik F, uji koefisien determinasi (R2), dan uji statistik t. Hasil pembuktian hipotesis dan pembahasan menunjukkan bahwa (1) hedonisme, religiusitas, motivasi, dan promosi secara simultan berpengaruh signifikan terhadap keputusan menabung. (2) Hedonisme secara parsial tidak berpengaruh signifikan terhadap keputusan menabung. (3) Religiusitas secara parsial berpengaruh signifikan terhadap keputusan menabung. (4) Motivasi secara parsial berpengaruh signifikan terhadap keputusan menabung. (5) Promosi secara parsial berpengaruh signifikan terhadap keputusan menabung.
\end{abstract}

Kata kunci : Keputusan Menabung, Hedonisme, Religiusitas, Motivasi, Promosi

\begin{abstract}
This study aims to analyze and obtain empirical evidence regarding the influence of hedonism, religiosity, motivation, and promotion on saving decision in sharia banks (a case study at PT Bank BRI Syariah, Tbk Majapahit Sub-Branch Office Semarang) either simultaneously or partially. The data used in this study was primary data collected using a questionnaire. The population in this study were all saving customers at PT Bank BRI Syariah, Tbk Majapahit Sub-Branch Office Semarang. The samples in this study amounted to 110 saving customers of PT Bank BRI Syariah, Tbk Majapahit SubBranch Office Semarang. The sampling technique used was accidental sampling. The data analysis model used multiple linear regression analysis model. While the data analysis technique used the $F$ statistical test, the coefficient of determination (R2), and the t statistical test. The results show that (1) hedonism, religiosity, motivation, and promotion simultaneously have a significant effect on saving decision. (2) Hedonism partially has no significant effect on saving decision. (3) Religiosity partially has a significant effect on saving decision. (4) Motivation partially has a significant effect on saving decision. (5) Promotion partially has a significant effect on saving decision
\end{abstract}

Keywords : Saving Decision, Hedonism, Religiosity, Motivation, Promotion. 


\section{PENDAHULUAN}

Melihat warga negara Indonesia yang mayoritas muslim, menjadikan bank syariah memiliki peluang yang sangat besar dalam menjangkau pangsa pasar. Namun pada kenyataannya, prosentase market share di Indonesia didominasi oleh perbankan konvensional. Terlihat dari prosentase market share per Juni 2020 yang masih didominasi oleh perbankan konvensional sebesar 93,82\% sedangkan perbankan syariah masih menunjukkan angka $6,18 \%$.

Di Indonesia, terdapat 4 bank umum persero yang mempunyai nama dan reputasi besar di kalangan masyarakat seperti PT Bank Rakyat Indonesia (Persero), Tbk; PT Bank Mandiri (Persero), Tbk; PT Bank Negara Indonesia (Persero), Tbk; dan PT Bank Tabungan Negara (Persero),. Kemudian dengan munculnya bank syariah pertama di Indonesia yaitu PT Bank Muamalat Indonesia, Tbk mendorong munculnya bank syariah yang lain. Terbukti hingga sekarang terdapat 14 bank umum syariah yang beroperasi.

Bukan hanya bank umum persero, pemerintah juga meresmikan bank umum syariah yakni PT Bank BRI Syariah, Tbk; PT Bank Syariah Mandiri; dan PT Bank BNI Syariah. Sedangkan Bank BTN Syariah masih menjadi unit usaha syariah dari PT Bank Tabungan Negara (Persero), Tbk. Dengan beroperasinya bank umum syariah tersebut, warga Indonesia yang mayoritas muslim dapat menjadi partisipan terbesar untuk kemajuan bank syariah di masa mendatang.

Pada 25 Oktober 2019, sebanyak 98 institusi keuangan syariah berhasil meraih "Infobank Sharia Institution Awards 2019". Ke-98 institusi keuangan peraih penghargaan terdiri atas 5 Bank Umum Syariah (BUS), 13 Unit Usaha Syariah (UUS) bank umum konvensional, 67 Bank Perkreditan Rakyat Syariah (BPRS), 5 Asuransi Jiwa Syariah (AJS), dan 8 Asuransi Umum Syariah (AUS). Penghargaan tersebut diberikan berdasarkan hasil rating Biro Riset Infobank (BIRI) terhadap laporan keuangan.

Biro Riset Infobank menggunakan empat pendekatan untuk melakukan rating institusi keuangan, yakni pendekatan rasio keuangan penting, pertumbuhan, Good Corporate Governance (GCG), dan profil risiko. Dari 14 BUS yang dirating, 5 BUS berhasil meraih predikat "Sangat Bagus". Predikat "Sangat Bagus" adalah predikat tertinggi dalam rating infobank. Lima BUS tersebut yakni 1) Bank Syariah Mandiri, 2) BTPN, 3) BCA Syariah, 4) BNI Syariah, dan 5) Bank Mega Syariah.

Berdasarkan daftar predikat tersebut, BUS di bawah kepemerintahan yakni PT Bank Syariah Mandiri dan PT Bank BNI Syariah mendapatkan penghargaan kecuali PT Bank BRI Syariah, Tbk. Jika dibandingkan dengan keduanya, seharusnya PT Bank BRI Syariah, Tbk dapat berada pada jajaran BUS yang meraih predikat "Sangat Bagus" dalam "Infobank Sharia Institution Awards 2019" dari pada BUS di bawah swasta nasional yakni BTPN, BCA Syariah, dan Bank Mega Syariah.

Salah satu pendekatan yang dilakukan Biro Riset Infobank adalah pertumbuhan Dana Pihak Ketiga (DPK). Apabila melihat dari perbandingan jumlah DPK, PT Bank BRI Syariah, Tbk juga masih belum bisa mengungguli PT Bank Syariah Mandiri dan PT Bank BNI Syariah. Hal tersebut dapat dilihat pada Tabel 1. 
Tabel 1. Perbandingan Jumlah DPK BSM, BNIS, dan BRIS (Miliar Rupiah)

\begin{tabular}{lccccccc}
\hline \multirow{2}{*}{ BANK } & \multicolumn{7}{c}{ TAHUN } \\
\cline { 2 - 8 } & $\mathbf{2 0 1 6}$ & $\mathbf{\%}$ & $\mathbf{2 0 1 7}$ & $\mathbf{\%}$ & $\mathbf{2 0 1 8}$ & $\mathbf{\%}$ & $\mathbf{2 0 1 9}$ \\
\hline Bank Syariah Mandiri & 69,95 & 11,37 & 77,90 & 12,28 & 87,47 & 13,65 & 99,41 \\
\hline Bank BNI Syariah & 24,23 & 21,25 & 29,38 & 20,79 & 35,49 & 6,08 & 37,65 \\
\hline Bank BRI Syariah & 21,99 & 19,65 & 26,31 & 9,69 & 28,86 & 18,23 & 34,12 \\
\hline \multicolumn{2}{c}{ Sumber: Annual Report } & BSM, BNIS, dan BRIS Tahun 2016-2019.
\end{tabular}

Berdasarkan perbandingan jumlah DPK dari tahun 2016-2019, terlihat bahwa PT Bank BRI Syariah, Tbk menjadi bank yang memiliki DPK paling kecil dibandingkan dengan PT Bank Syariah Mandiri dan PT Bank BNI Syariah. Meskipun setiap tahun DPK PT Bank BRI Syariah, Tbk meningkat, namun secara prosentase mengalami penurunan pada tahun 2017 ke 2018. Hal ini menunjukkan bahwa PT Bank BRI Syariah, Tbk belum maksimal dalam menjaga eksistensinya sebagai bank syariah terbaik di Indonesia.

Berdasarkan data tersebut menandakan bahwa masih terdapat masalah yang harus diantisipasi oleh PT Bank BRI Syariah, Tbk untuk meningkatkan keputusan menabung. Keputusan adalah sebuah proses pendekatan terhadap penyelesaian masalah yang terdiri dari pengenalan masalah, mencari informasi, beberapa penelitian alternatif, membuat keputusan membeli dan perilaku setelah membeli yang dilalui konsumen (Kotler dan Armstrong, 2008). Menurut Maski (2010) perilaku nasabah dapat mencerminkan seseorang dalam melakukan pembelian produk dan jasa. Selain itu nasabah juga memperhatikan kualitas pelayanan serta produk yang ditawarkan sehingga nasabah termotivasi untuk menggunakannya. Menurut Siregar (2018) dalam menawarkan produk yang dimiliki, bank juga menginformasikan kepada masyarakat melalui kegiatan promosi. Dengan diadakannya kegiatan promosi maka masyarakat akan mengetahui manfaat apa yang didapatkan. Dalam hal ini keputusan menabung dapat dipengaruhi oleh berbagai faktor, faktor yang memungkinkan dapat mempengaruhi keputusan menabung antara lain hedonisme, religiusitas, motivasi, dan promosi.

\section{TINJAUAN PUSTAKA}

\section{Keputusan Menabung}

Keputusan adalah proses pemilihan satu tindakan dari dua atau lebih alternatif, yang berawal dari latar belakang masalah, identifikasi masalah, hingga terbentuknya kesimpulan berdasarkan pertimbangan dan kriteria tertentu (Siregar, 2018). Ali (2017) mendefinisikan keputusan nasabah untuk menabung merupakan efek akhir dari suatu pembelian yang diartikan sebagai suatu sikap dan niat untuk berperilaku di masa depan dan diekspresikan melalui hal-hal seperti, komitmen untuk membeli produk dari perusahaan jika membutuhkan produk lainnya, komitmen untuk memberikan rekomendasi pada orang lain, niat untuk menambah jumlah tabungan, niat atau keinginan memberikan hal-hal positif perusahaan.

Indikator variabel keputusan menabung dalam penelitian ini merujuk pada Kotler dan Armstrong (2008) yaitu: Pengenalan Masalah, Pencarian Informasi, Evaluasi Alternatif, Keputusan Pembelian, dan Perilaku Setelah Pembelian.

\section{Hedonisme}

Takariani (dalam Kelly, 2015) menyebutkan bahwa hedonisme berasal dari bahasa Yunani hedone (kenikmatan, kegembiraan) yang berarti adalah gaya hidup yang menjadikan kenikmatan atau kebahagiaan sebagai tujuan. 
Pemahaman makna hedonisme menurut Epicurus (2019) melibatkan pilihan yaitu kesenangan dan penghindaran rasa sakit. Kesenangan yang sesungguhnya dapat dicapai jika terlepas dari penderitaan jasmani dan rohani. Kesenangan bagi Epicurus harus diperoleh dengan cara bijak dalam menyikapi keinginan, ada kalanya beberapa kesenangan harus dilepaskan terutama jika diikuti oleh terlalu banyak kesusahan. Seseorang harus bertindak dengan mempertimbangkan kesenangan dengan derita. Tindakan terhitung bijak jika dalam jangka panjang menghasilkan lebih banyak kesenangan dibandingkan penderitaan.

Indikator variabel hedonisme dalam penelitian ini merujuk pada Suprapti (2010) yaitu: Aktivitas, Minat, dan Opini.

\section{Religiusitas}

Menurut Glock dan Rodney (dalam Maisur, et al, 2015) religiusitas adalah keadaan yang terdapat dalam diri seseorang yang mendorong berpikir, bersikap, berperilaku, dan bertindak sesuai dengan ajaran agamanya.

Indikator variabel religiusitas dalam penelitian ini merujuk pada Glock dan Rodney (dalam Maisur, et al, 2015) yaitu: Keyakinan/Ideologis, Praktik Agama/ Ritualistik, Pengalaman/Eksperiensial, Pengetahuan Agama/Intelektual, dan Konsekuensi.

\section{Motivasi}

Menurut Schiffman dan Kanuk (dalam Nitisusastro, 2012) motivasi digambarkan sebagai dorongan dari dalam diri individu seseorang dan memaksa dia untuk berbuat. Dorongan ini dihasilkan oleh tekanan yang timbul akibat dari satu kebutuhan yang tidak terpenuhi. Nitisusastro (2012) menambahkan ternyata terdapat korelasi antara motivasi dan kebutuhan. Jadi dapat disimpulkan bahwa motivasi menimbulkan dorongan agar kebutuhan seseorang terpenuhi.

Indikator variabel motivasi dalam penelitian ini merujuk pada Maslow (dalam Suprapti, 2010) yaitu: Kebutuhan Fisiologis, Kebutuhan Rasa Aman, Kebutuhan Sosial, Kebutuhan Ego, dan Kebutuhan Aktualisasi Diri.

\section{Promosi}

Menurut Ali (2017) promosi salah satu kegiatan pemasaran yang sangat penting untuk mempengaruhi konsumen yang dilaksanakan oleh perusahaan untuk memasarkan produk-produknya agar konsumen mengenal dan menjadi senang dengan produk-produk yang dipromosikan sehingga mau membelinya. Sedangkan menurut Tajudin dan Mulazid (2017) promosi adalah kegiatan mengkomunikasikan atau menginformasikan manfaat dari sebuah produk dan jasa kepada konsumen untuk mendorong dan membujuk konsumen untuk membeli produk dan jasa tersebut.

Indikator variabel promosi dalam penelitian ini merujuk pada Kotler dan Armstrong (2008) yaitu: Periklanan, Promosi Penjualan, Hubungan Masyarakat dan Penjualan Pribadi.

\section{METODE PENELITIAN}

Desain penelitian yang digunakan dalam penelitian ini adalah penelitian kuantitatif terapan kausal. Data primer yang digunakan dalam penelitian ini diperoleh dari kuesioner yang disebar kepada nasabah tabungan pada PT Bank BRI Syariah, Tbk KCP Majapahit Semarang. Data sekunder yang digunakan dalam penelitian ini diperoleh dari jurnal penelitian, buku-buku referensi, majalah, serta website. Metode pengumpulan data yang digunakan dalam penelitian ini adalah metode kuesioner dan studi dokumenter.

Populasi dalam penelitian ini adalah seluruh nasabah tabungan pada PT 
Bank BRI Syariah, Tbk KCP Majapahit Semarang. Jumlah sampel dalam penelitian ini adalah 110 responden. Teknik pengambilan sampel yang digunakan dalam penelitian ini dengan pendekatan non probability sampling. Jenis atau metode sampling yang digunakan adalah accidental sampling.
Dalam penelitian ini menggunakan model analisis regresi linier berganda.

\section{HASIL PENELITIAN}

Adapun hasil uji statistik $\mathrm{F}$, uji koefisien determinasi $\left(\mathrm{R}^{2}\right)$, dan uji statistik $\mathrm{t}$ dalam penelitian ini terdapat pada Tabel 2, Tabel 3, dan Tabel 4.

Tabel 2. Hasil Uji Statistik F

\begin{tabular}{|c|c|c|c|c|c|c|}
\hline \multicolumn{7}{|c|}{ ANOVA $^{\mathrm{a}}$} \\
\hline & Model & $\begin{array}{c}\text { Sum of } \\
\text { Squares }\end{array}$ & Df & $\begin{array}{c}\text { Mean } \\
\text { Square }\end{array}$ & $\mathbf{F}$ & Sig. \\
\hline \multirow[t]{3}{*}{1} & Regression & 3081,259 & 4 & 770,315 & 71,319 & $0,000^{\mathrm{b}}$ \\
\hline & Residual & 1118,414 & 105 & 10,652 & & \\
\hline & Total & 4199,673 & 109 & & & \\
\hline & Depender & Keputusan_ & ung & & & \\
\hline
\end{tabular}

Sumber: Data primer yang diolah (2020)

Tabel 3. Hasil Uji Koefisien Determinasi $\left(\mathbf{R}^{2}\right)$

\begin{tabular}{|c|c|c|c|c|}
\hline \multicolumn{5}{|c|}{ Model Summary $^{b}$} \\
\hline Model & $\mathbf{R}$ & R Square & $\begin{array}{c}\text { Adjusted R } \\
\text { Square }\end{array}$ & $\begin{array}{l}\text { Std. Error of the } \\
\text { Estimate }\end{array}$ \\
\hline 1 & $0,857^{\mathrm{a}}$ & 0,734 & 0,724 & 3,264 \\
\hline Pred & $\operatorname{tant}), \operatorname{Pr}$ & onisme, Rel & Motivasi & \\
\hline Depe & le : Kep & nabung & & \\
\hline
\end{tabular}

Sumber: Data primer yang diolah, (2020)

Tabel 4. Hasil Uji Statistik t

\begin{tabular}{|c|c|c|c|c|c|c|}
\hline \multicolumn{7}{|c|}{ Coefficients $^{\mathrm{a}}$} \\
\hline & \multirow[t]{2}{*}{ Model } & \multicolumn{2}{|c|}{$\begin{array}{l}\text { Unstandardized } \\
\text { Coefficients }\end{array}$} & \multirow{2}{*}{$\begin{array}{c}\begin{array}{c}\text { Standardized } \\
\text { Coefficients }\end{array} \\
\text { Beta } \\
\end{array}$} & \multirow[t]{2}{*}{$\mathbf{T}$} & \multirow[t]{2}{*}{ Sig. } \\
\hline & & B & Std. Error & & & \\
\hline \multirow[t]{5}{*}{1} & (Constant) & $-5,984$ & 3,521 & & $-1,699$ & 0,092 \\
\hline & Hedonisme & 0,092 & 0,052 & 0,094 & 1,782 & 0,078 \\
\hline & Religiusitas & 0,194 & 0,089 & 0,127 & 2,185 & 0,031 \\
\hline & Motivasi & 0,398 & 0,091 & 0,380 & 4,357 & 0,000 \\
\hline & Promosi & 0,574 & 0,119 & 0,417 & 0,816 & 0,000 \\
\hline
\end{tabular}

a. Dependent Variable : Keputusan_Menabung

Sumber: Data primer yang diolah, (2020)

\section{PEMBAHASAN}

\section{Pengaruh Hedonisme Keputusan Menabung}

Berdasarkan hasil uji t pada Tabel 4 dihasilkan thitung untuk variabel hedonisme $=1,782<$ ttabel $=1,987$ atau signifikansi $=0,078>0,05$. Dengan demikian dapat disimpulkan bahwa variabel hedonisme secara parsial tidak berpengaruh signifikan terhadap keputusan menabung pada PT Bank BRI Syariah, Tbk KCP Majapahit Semarang.

Semula diduga variabel hedonisme secara parsial berpengaruh signifikan terhadap keputusan menabung. Hal ini didasari pandangan Kasali (dalam Rizaldi, 2016) yang menyatakan bahwa gaya hidup akan mempengaruhi keinginan seseorang untuk berperilaku dan akhirnya menentukan pilihan-pilihan konsumsi 
seseorang. Salah satu gaya hidup di sini adalah hedonisme, dimana hedonisme merupakan gaya hidup yang diperoleh dengan mencari perasaan-perasaan yang bersifat menyenangkan dan sedapat mungkin menghindari perasaan-perasaan yang tidak mengenakkan (Epicurus, 2019). Ismail (2019) menjelaskan, pada dasarnya mengejar kesenangan menurut Epikuros tidak seperti hedonisme yang dipahami sekarang ini. Hedonisme Epikuros tidak identik dengan rakus dan banyak harta, tetapi kenikmatan yang dimaksud adalah sesuatu yang menyenangkan dan manusia dapat terhindar dari kesulitan serta kesedihan. Dengan demikian, hedonisme menurut Epicurus lebih membatasi keinginankeinginan manusia agar menimbulkan ketenangan untuk mencapai kenikmatan (Sudarsih, 2011). Pembatasan keinginan dapat dilakukan dengan menghindari sifat boros dan senantiasa berhemat untuk mempersiapkan masa depan. Dalam hal ini salah satu keputusan yang tepat untuk dilakukan adalah dengan cara menabung.

Namun, hasil penelitian ini menunjukkan hedonisme secara parsial tidak berpengaruh signifikan terhadap keputusan menabung. Hal ini berarti peningkatan atau penurunan perilaku hedonisme tidak memiliki pengaruh yang signifikan terhadap keputusan menabung nasabah. Dalam hal ini, ketika nasabah memutuskan untuk menabung maka pertimbangan yang dilakukan karena adanya kebutuhan atau tujuan yang ingin dicapai, sehingga perilaku hedonisme berpengaruh signifikan terhadap keputusan menabung.

Hasil penelitian ini kontradiksi dengan penelitian yang dilakukan oleh Indrawati (2015) dan Rizaldi (2016) yang menjelaskan bahwa variabel hedonisme berpengaruh signifikan terhadap keputusan pembelian. Namun sejalan dengan hasil penelitian yang dilakukan oleh Umboh, et al, (2015) yang menyatakan bahwa life style tidak berpengaruh signifikan terhadap keputusan pembelian, dimana dalam penelitian ini hedonisme merupakan bagian dari life style.

\section{Pengaruh Religiusitas Terhadap Keputusan Menabung}

Berdasarkan hasil uji t pada Tabel 4 dihasilkan $t_{\text {hitung }}$ untuk variabel religiusitas $=2,185>\mathrm{t}_{\text {tabel }}=1,987$ atau signifikansi $=0,031<0,05$. Dengan demikian dapat disimpulkan bahwa variabel religiusitas secara parsial berpengaruh signifikan terhadap keputusan menabung pada PT Bank BRI Syariah, Tbk KCP Majapahit Semarang.

Hal ini sejalan dengan pandangan Hassan (dalam Maisur, et al, 2015) yang menjelaskan bahwa perilaku ekonomi sangat ditentukan oleh tingkat keimanan seseorang atau masyarakat. Perilaku ini kemudian membentuk kecenderungan perilaku konsumsi dan produksi di pasar. Perspektif tersebut juga berpengaruh terhadap perilaku menabung. Sehingga semakin religius seseorang, berarti semakin sering menjalankan perintah dalam Islam serta menjauhi laranganlarangannya pula. Dalam hal ini, kereligiusan seseorang pasti akan berpengaruh pada perilaku konsumsinya. Sehingga keputusan untuk menabung juga akan semakin tinggi apabila diikuti dengan tingkat religiusitas yang tinggi pula.

Hasil penelitian ini mendukung penelitian terdahulu yang dilakukan oleh Maisur, et al (2015), Shofwa (2016), Pabbajah, et al (2019), dan Wijaya, et al (2019) yang menyatakan bahwa religiusitas berpengaruh signifikan terhadap keputusan menabung.

\section{Pengaruh Motivasi Terhadap Keputusan Menabung}

Berdasarkan hasil uji t pada Tabel 4 dihasilkan $t_{\text {hitung }}$ untuk variabel motivasi 
$=4,357>\mathrm{t}_{\text {tabel }}=1,987$ atau signifikansi $=$ $0,000<0,05$. Dengan demikian dapat disimpulkan bahwa variabel motivasi secara parsial berpengaruh signifikan terhadap keputusan menabung pada PT Bank BRI Syariah, Tbk KCP Majapahit Semarang.

Hal ini sejalan dengan pandangan Nitisusastro (2012) yang menjelaskan bahwa pengaruh motivasi terhadap perilaku konsumen adalah timbulnya kebutuhan dan keinginan untuk memiliki sesuatu produk barang atau jasa. Dorongan kebutuhan dan keinginan tersebut akan menjadi lebih kuat apabila barang atau jasa yang ditawarkan sesuai dengan kepribadiannya, mengandung atau menyimpan pengalaman yang memuaskan dan dipersepsikan secara baik. Lebih lanjut Mandali, et al (2016) menyatakan bahwa semakin tinggi motivasi seseorang maka semakin tinggi pula kemungkinan konsumen memutuskan untuk menabung. Dorongan kebutuhan seseorang menjadi pendorong utama dalam membuat keputusan. Pembelian produk dengan didasari motivasi yang lebih kuat akan menimbulkan keputusan pembelian yang lebih signifikan khususnya pada keputusan menabung di bank syariah.

Hal ini mendukung penelitian terdahulu yang dilakukan oleh Utami, et al (2015), Mayasari, et al (2017), dan Septianan L dan Indrajaya (2018) yang menyatakan bahwa motivasi berpengaruh signifikan terhadap keputusan menabung serta Dahana, et al (2020) yang menyatakan bahwa motivasi berpengaruh signifikan terhadap keputusan pembelian.

\section{Pengaruh Promosi Terhadap Keputusan Menabung}

Berdasarkan hasil uji t pada Tabel 4 dihasilkan $t_{\text {hitung }}$ untuk variabel promosi $=4,816>\mathrm{t}_{\text {tabel }}=1,987$ atau signifikansi $=$ $0,000<0,05$. Dengan demikian dapat disimpulkan bahwa variabel promosi secara parsial berpengaruh signifikan terhadap keputusan menabung pada PT Bank BRI Syariah, Tbk KCP Majapahit Semarang.

Hal ini sejalan dengan pandangan Siregar (2018) yang menjelaskan bahwa promosi merupakan salah satu sarana pemasaran perusahaan yang bertujuan untuk mengenalkan produk yang dipasarkan kepada konsumen, sehingga diharapkan dapat meningkatkan volume penjualan. Dalam hal ini promosi sangat penting dalam mengenalkan produk tabungan bank syariah untuk meningkatkan keputusan menabung konsumen. Lebih lanjut Sarwita (2017) menambahkan bahwa promosi dan keputusan nasabah memiliki hubungan yang sangat erat karena penilaian dari keputusan nasabah salah satunya tergantung pada promosi yang dilakukan oleh perusahaan yang pada dasarnya mencakup harapan dan hasil yang ingin dicapai dan dirasakan.

Hal ini mendukung penelitian terdahulu yang dilakukan oleh Tajudin dan Mulazid (2017), Siregar (2018), dan Utamy dan Widhiastuti (2019) yang menyatakan bahwa promosi berpengaruh signifikan terhadap keputusan menabung serta Bansal, et al (2014) yang menyatakan bahwa promosi berpengaruh signifikan terhadap keputusan pembelian.

\section{KESIMPULAN}

Penelitian ini bertujuan untuk menganalisis dan mendapatkan bukti empiris mengenai pengaruh hedonisme, religiusitas, motivasi, dan promosi terhadap keputusan menabung pada bank syariah (studi kasus pada PT Bank BRI Syariah, Tbk Kantor Cabang Pembantu Majapahit Semarang) baik secara simultan maupun parsial. Secara simultan, hedonisme, religiusitas, motivasi, dan promosi berpengaruh signifikan terhadap keputusan menabung. Namun secara parsial, religiusitas, motivasi, dan promosi berpengaruh signifikan terhadap 
keputusan menabung. Sedangkan hedonisme secara parsial tidak berpengaruh signifikan terhadap keputusan menabung. Berdasarkan hasil uji koefisien determinasi $\left(\mathrm{R}^{2}\right)$ menunjukkan nilai Adjusted $R$ Square sebesar 0,724 atau $72,4 \%$. Hal ini menunjukkan bahwa variabel hedonisme, religiusitas, motivasi, dan promosi memberikan kontribusi pengaruh terhadap keputusan menabung sebesar 72,4\%. Sedangkan sisanya dipengaruhi oleh variabel lain yang tidak diteliti dalam penelitian ini. Keterbatasan penelitian ini adalah (1) faktor-faktor yang mempengaruhi keputusan menabung dalam penelitian ini hanya terdiri dari empat variabel yaitu hedonisme, religiusitas, motivasi, dan promosi, sedangkan masih banyak faktor lain yang mempengaruhi keputusan menabung, (2) hasil uji model regresi terdapat satu variabel yang tidak signifikan yaitu hedonisme. Pada penelitian selanjutnya diharapkan (1) menambah variabelvariabel independen lain yang dapat mempengaruhi keputusan menabung pada bank syariah dan belum digunakan dalam penelitian ini, (2) berkaitan dengan variabel hedonisme yang tidak signifikan, diharapkan dapat dilakukan penelitian lebih lanjut oleh peneliti selanjutnya.

\section{DAFTAR PUSTAKA}

Ali, K. 2017. Pengaruh Promosi dan Atribut Produk Terhadap Keputusan Nasabah dalam Memilih Tabungan Ekasave Pada Bank Eka Kantor Pusat Metro. Jurnal DINAMIKA, 3(1), 66-80.

Bansal, S. P., Singh, R., \& Gangotia, A. 2014. Measuring the Impact of Sales Promotion, Service Quality and Customer Experience: A Case of eTicketing. Transnational Corporations Review, 6(4), 419428.
Dahana, W. D., Miwa, Y., Baumann, C., \& Morisada, M. 2020. Relative Importance Of Motivation, Store Patronage, and Marketing Efforts in Driving Cross-Buying Behaviors. Journal of Strategic Marketing, 129.

Epicurus. 2019. Seni Berbahagia. BASABASI. Yogyakarta.

Indrawati, D. 2015. Pengaruh Citra Merek dan Gaya Hidup Hedonis Terhadap Keputusan Pembelian Jilbab “ZOYA." Jurnal Riset Ekonomi dan Manajemen, 15(2), 302-319.

Ismail, M. 2019. Hedonisme dan Pola Hidup Islam. Jurnal Ilmiah Islamic Resources, 16(2), 193-204.

Kelly, E. 2015. Gaya Hidup Hedonis dan Impulse Buying Pada Kalangan Remaja Putri. Jurnal Sketsa Bisnis, 2(1), 1-18.

Kotler, P., \& Armstrong, G. 2008. Principles of Marketing (12., rev. ed., internat. ed). Pearson/Prentice Hall. United States of America.

Maisur, Arfan, M., \& Shabri, M. 2015. Pengaruh Prinsip Bagi Hasil, Tingkat Pendapatan, Religiusitas, dan Kualitas Pelayanan Terhadap Keputusan Menabung Nasabah Pada Bank Syariah di Banda Aceh. Jurnal Magister Akuntansi, 4(2), 1-8.

Mandali, R., Rahmiati, \& Mesta, H. A. 2016. Pengaruh Faktor Psikologis Terhadap Keputusan Menabung Mahasiswa Pada Bank Syariah di Universitas Negeri Padang. Jurnal Kajian Manajemen Bisnis, 5(1), 118-131.

Maski, G. 2010. Analisis Keputusan Nasabah Menabung: Pendekatan Komponen dan Model Logistik Studi Pada Bank Syariah di Malang. 
Journal of Indonesian Applied Economics, 4(1), 43-57.

Mayasari, H., Nurlina, \& Wardiningsih, E. 2017. Pengaruh Motivasi dan Kualitas Pelayanan Terhadap Keputusan Menabung di Bank Sinarmas Syariah Padang. Jurnal Manajemen dan Kewirausahaan, $8(2), 1-13$.

Nitisusastro, H. M. 2012. Perilaku Konsumen: Dalam Perspektif Kewirausahaan. Alfabeta. Bandung.

Pabbajah, M., Widyanti, R. N., \& Widyatmoko, W. F. 2019. The Factors of Service, Religiosity, and Knowledge in The Decision of Customers to Save Funds in Sharia Banks in Yogyakarta City. International Journal of Business, Humanities, Education, and Social Sciences, 1(2), 13-26.

Rizaldi, M. 2016. Pengaruh Gaya Hidup Hedonis Terhadap Keputusan Pembelian Pada Smartphone di Kalangan Mahasiswa Studi Pada Mahasiswa Fakultas Ekonomi Universitas Negeri Surabaya. Jurnal Ilmu Manajemen, 4(2), 85-93.

Sarwita, H. A. 2017. Pengaruh Kualitas Pelayanan dan Promosi Terhadap Keputusan Nasabah untuk Menabung (Studi Kasus Pada Perumda BPR Majalengka). Jurnal Ilmiah Manajemen dan Akuntansi, 4(1), 36-45.

Septianan L, E., \& Indrajaya, T. 2018. Analisis Pengaruh Motivasi Terhadap Keputusan Konsumen untuk Menabung BRI Simpedes di BRI Unit Cipayung. Jurnal Administrasi dan Manajemen, 11(1), 715-722.

Shofwa, Y. 2016. Pengaruh Kualitas Produk dan Religiusitas Terhadap
Keputusan Nasabah Produk Simpanan Pada BSM Cabang Purwokerto. El-jizya: Jurnal Ekonomi Islam, 4(1), 189-215.

Siregar, B. G. 2018. Pengaruh Produk dan Promosi Terhadap Keputusan Menjadi Nasabah Tabungan Marhamah Pada PT Bank Sumut Cabang Syariah Padangsidimpuan. TAZKIR: Jurnal Penelitian Ilmuilmu Sosial dan Keislaman, 4(1), 120.

Sudarsih, S. 2011. Konsep Hedonisme Epikuros dan Situasi Indonesia Masa Kini. HUMANIKA, 14(1), 1-8.

Suprapti, N. W. S. 2010. Perilaku Konsumen: Pemahaman Dasar dan Aplikasinya dalam Strategi Pemasaran. Udayana University Press. Bali.

Tajudin, M. H., \& Mulazid, A. S. 2017. Pengaruh Promosi, Kepercayaan, dan Kesadaran Merek Terhadap Keputusan Nasabah Menggunakan Produk Tabungan Haji (Mabrur) Bank Syariah Mandiri KCP Sawangan Kota Depok. ISLAMICONOMIC: Jurnal Ekonomi Islam, 8(1), 19-46.

Umboh, S. O., Tumbel, A., \& Soepeno, D. 2015. Analisis Kualitas Produk, Brand Image, dan Life Style Terhadap Keputusan Pembelian Pakaian Wanita di Mississippi Manado Town Square. Jurnal EMBA, 3(1), 1096-1105.

Utami, W., Sangen, M., \& Rachman, M. Y. 2015. Analisis Pengaruh Religiusitas, Kelompok Referensi, dan Motivasi Terhadap Keputusan Menabung di Bank Syariah (Studi Pada Nasabah Bank Syariah di Kota Banjarmasin). Jurnal Wawasan Manajemen, 3(1), 79-89. 
Utamy, O. D. B., \& Widhiastuti, R. 2019. The Effect of Sharia Bank Knowledge, Promotion, and Facilities on Savings Decisions at Sharia Banks with Savings Interest as Mediation Variables. Journal of Islamic Economics, Management, and Business, 1(1), 1-28.

Wijaya, I. F., Hakim, A. R., Saputro, N., \& Mulyadi. 2019. Religiosity Level and Saving Decisions in Baitul Maal wat Tamwil: The Case Of Indonesia. Journal of Islamic Marketing, 11(6), 1465-1483. 